\title{
"Falta de fechamento": conflitos profissionais e centralidade dos procedimentos de segurança no sistema socioeducativo do Rio de Janeiro
}

Juliana Vinuto (orcid.org/0000-0002-6035-4463), Universidade Federal Fluminense, Rio de Janeiro, Rio de Janeiro, Brasil'.

Joana Domingues Vargas (https://orcid.org/0000-0001-5714-9568), Universidade Federal do Rio de Janeiro, Rio de Janeiro, Rio de Janeiro, Brasil".

Hebe Signorini Gonçalves (https://orcid.org/0000-0003-1688-9927), Universidade Federal do Rio de Janeiro, Rio de Janeiro, Rio de Janeiro, Brasil"'.

Resumo: No intuito de compreender as relações entre os objetivos considerados como inconciliáveis por profissionais que atuam na medida socioeducativa de internação, este artigo analisará as discussões sobre falta de fechamento, categoria mobilizada por agentes de segurança socioeducativa para indicar a disjunção e a desconfiança entre diferentes grupos profissionais. A partir de experiências diversas de pesquisa, será possível constatar que os conflitos em torno da falta de fechamento revelam um contexto organizacional em que cada grupo pode fazer o trabalho do modo como considera mais adequado, sem prestar contas uns aos outros, o que permite que aqueles que atuam de modo dissociado dos discursos oficiais nem sempre sejam responsabilizados por isso. Tal contexto ajuda a compreender a produção cotidiana da centralidade atribuída aos procedimentos de segurança na medida socioeducativa de internação, já que as atividades socioeducativas só são implementadas quando não conflitam com os objetivos de controle e disciplina ou em ocasiões em que a instituição tenta auferir algum lucro simbólico a partir da perspectiva socioeducativa.

Palavras-chave: Medida Socioeducativa de Internação; Disjunção; Desconfiança, Punição, Segurança.

\section{"Falta de fechamento": \\ professional conflicts and the centrality of security procedures in Rio de Janeiro's juvenile detention system}

Abstract: In order to understand the relationships between goals considered irreconcilable by professionals that works in the juvenile detention system, this article will analyze the discussions about falta de fechamento, a category mobilized by juvenile detention officers to indicate the disjunction and mistrust between different professional groups. From diverse research experiences, it

\author{
I. Juliana Vinuto \\ é doutora em \\ sociologia pelo \\ Programa de \\ Pós-Graduação \\ em Sociologia e \\ Antropologia da \\ Universidade Federa \\ do Rio de Janeiro. \\ Pesquisadora de \\ Pós-Doutorado \\ pelo Programa de \\ Pós-Graduação em \\ Antropologia da \\ Universidade Federa \\ Fluminense, Rio de \\ Janeiro, RJ, Brasil. \\ <j.vinuto@gmail. \\ com>.
}

II. Joana Domingues Vargas é doutora em sociologia pelo Instituto Universitário de Pesquisas do Rio de Janeiro (luperj), Brasil. Professora

Associada II da Universidade Federal do Rio de Janeiro. <jovargas@uol.com. br>.

III. Hebe Signorini Gonçalves é doutora em psicologia clínica pela Pontifícia

Universidade Católica do Rio de Janeiro. Professora Associada Il da Universidade Federal do Rio de Janeiro.

$<$ hebe@globo.com>. 
1. Para saber mais sobre o Degase, consultar <http:// www.degase.rj.gov. $\mathrm{br} />$. Acesso em 16 Set. 2021

2. Segundo o Estatuto da Criança e do Adolescente (ECA, Lei Federal 8.069, de 13 de julho de 1990), quando um indivíduo com idade entre 12 e 18 anos incompletos comete um ato infracional (ação análoga a crime ou contravenção penal), pode ser responsabilizado por determinação judicial a cumprir medidas socioeducativas.

As medidas socioeducativas existentes são: advertência; obrigação de reparação do dano, prestação de serviços à comunidade, liberdade assistida, inserção em regime de semiliberdade ou internação em estabelecimento educacional.

A medida socioeducativa de internação é considerada a mais grave, sendo a única privativa de liberdade.

3. Para esse problema, uma vertente da sociologia das organizações tem oferecido resposta diferenciada, mostrando que é prospectivamente que os membros da organização reconstroem, por meio de relatos, a adequação de suas práticas às regras previstas (Bittner 2013). will be possible to observe that the conflicts around falta de fechamento reveal an organizational context in which each group can do the work as it sees fit without being accountable to each other, which allows those who act in a manner dissociated from official discourses not always to be held accountable for it. This context helps to understand the daily production of the centrality given to security procedures in the juvenile detention system, since the educational activities are only implemented when they do not conflict with the objectives of control and discipline or on occasions when the institution tries to make some symbolic profit from the educational perspective

Keywords: Socio-educational internment measure. Disjunction. Distrust. Punishment. Security.

\section{Considerações iniciais}

Profissionais que realizam uma mesma função nem sempre estão de acordo com a maneira como deve ser feito o seu trabalho. Esse é um tema particularmente explorado na literatura sobre polícia, que identifica estilos diferentes de atuação (Bittner, 1990; Bayley, 2001). Pretende-se mostrar, neste artigo, que esse aspecto se torna ainda mais relevante em funções que objetivam o atendimento de objetivos considerados contraditórios pelos próprios trabalhadores responsáveis por sua execução. Esse é o caso dos agentes de segurança socioeducativa do Departamento Geral de Ações Socioeducativas (Degase) ${ }^{1}$, instituição responsável pela execução das medidas socioeducativas ${ }^{2}$ de semiliberdade e internação no estado do Rio de Janeiro. Como veremos, esses profissionais vivenciam de forma mais intensa os diferentes objetivos colocados às instituições que lidam com adolescentes considerados em conflito com a lei.

Outro aspecto geralmente abordado nas discussões sobre instituições de ordem e controle é o descolamento parcial, ou às vezes total, entre a função oficial de uma dada instituição, definida por regras, documentos, decretos e discursos oficiais, e as práticas profissionais realizadas cotidianamente ${ }^{3}$. No caso das medidas socioeducativas, o Sistema Nacional de Atendimento Socioeducativo (Sinase, Lei Federal 12.594, de 18 de janeiro de 2012), em seu artigo 1으, § 2으, afirma que estas objetivam:

I - a responsabilização do adolescente quanto às consequências lesivas do ato infracional, sempre que possível incentivando a sua reparação;

II- a integração social do adolescente e a garantia de seus direitos individuais e sociais, por meio do cumprimento de seu plano individual de atendimento; e

III- a desaprovação da conduta infracional, efetivando as disposições da sentença como parâmetro máximo de privação de liberdade ou restrição de direitos, observados os limites previstos em lei (grifos nossos). 
É possível observar que as medidas socioeducativas almejam atender a um duplo objetivo sancionatório-educativo (Vinuto \& Duprez, 2019), a partir do qual se espera responsabilizar o adolescente com uma sanção, mas esta não pode ser puramente punitiva, mas de caráter educativo com o objetivo de reintegração social. Esses objetivos se tornam mais contraditórios quando olhamos para a medida socioeducativa de internação, que será o foco deste artigo. Isso ocorre porque, por se tratar de uma medida realizada com base na privação de liberdade, o trabalho de "integração social do adolescente" se torna quase uma contradição. Desse modo, na medida de internação há um problema adicional na análise sobre a relação entre regras formais e sua aplicação prática, tendo em vista a tensão entre os dois objetivos prescritos que são, muitas vezes, entendidos como "inconciliáveis" pelos próprios operadores (Gonçalves, Sereno \& Abreo, 2017): a segurança e a socioeducação.

São muitos os profissionais que atuam em um centro de internação: psicólogos, assistentes sociais, professores, médicos etc. Mas nenhum tem o seu trabalho tão profundamente atravessado pelo duplo objetivo sancionatório-educativo quanto o agente de segurança socioeducativa. Enquanto os demais profissionais interagem com os adolescentes internados sobretudo em momentos previamente agendados, por vezes tendo sua circulação restrita nos diferentes espaços das unidades (Hernandez, 2018), os agentes de segurança socioeducativa - nominados apenas de "agentes", termo que também será mobilizado neste texto - acompanham todas as atividades realizadas pelos adolescentes, como as refeições, as aulas, audiências, oficinas, a instrução religiosa, dentre outros. Ademais, esses profissionais trabalham em uma carga horária de 24 horas seguidas com 36 horas de descanso, assim, estão dia e noite com o adolescente - ao contrário dos demais profissionais, cuja jornada de trabalho costuma ser oficialmente encerrada ao fim do dia (Abreo, 2017; Meireles, 2017; Sereno, 2015).

Somado a isso, enquanto os demais profissionais podem se dedicar a trabalhos exclusivamente relacionados à "ressocialização" ${ }^{4}$, os agentes são os únicos servidores responsáveis também pelas funções de contenção, controle e ordem. Nesse contexto, alguns agentes reclamam da falta de tempo para planejar e executar atividades socioeducativas, já que sua rotina laboral é, prioritariamente, fazer segurança: evitar fugas e conflitos entre adolescentes, obrigá-los a permanecer com as mãos para trás e a cabeça baixa como forma de prevenção de conflitos, abrir e fechar cadeados, levar os adolescentes às atividades organizando-os em fila indiana, desautorizar atividades com portas fechadas, dentre outros.

Essas diferenças entre o que fazem os agentes de segurança socioeducativa e os demais servidores que atuam nos centros de internação do Rio de Janeiro produzem

\footnotetext{
4. Termo nativo mobilizado por profissionais e ativistas envolvidos na defesa de direitos de crianças e adolescentes. $\mathrm{O}$ uso desse termo não significa, aqui, que partamos da premissa de que a socialização (sobretudo familiar) do adolescente internado foi deficitária ou incorreta, o que abriria espaço para o argumento moral de que instituições de medida socioeducativa devem "ressocializar" o adolescente de um modo supostamente mais "correto", de acordo com valores aceitos socialmente (Batista, 2009). Ao contrário, o termo é utilizado para destacar o objetivo legalmente manifesto das medidas socioeducativas e os discursos profissionais em torno destas.
} 
5. O termo "menor" era oficialmente empregado no extinto Código de Menores para se referir tanto ao adolescente que cometia atos infracionais como aos adolescentes que viviam outras situações de vulnerabilidade social. Desde que o ECA entrou em vigor, este termo é considerado inapropriado, mas, apesar disso, é comum o seu uso corriqueiro, sobretudo por aqueles que o mobilizam de modo estigmatizante como é, aliás, o caso do agente de segurança socioeducativa entrevistado. Para análises sobre o termo "menor" como categoria acusatória historicamente construída, ver Érica Santos (2014). conflitos e negociações cotidianas entre esses profissionais sobre o que deveria ser a medida socioeducativa de internação e, consequentemente, sobre como deveria ser o trabalho prático cotidiano dos agentes. Este artigo almeja analisar alguns desses conflitos e discutir como os agentes de segurança socioeducativa agem em um contexto em que as regras institucionais são vistas como conflitantes. Para tanto, iremos nos valer da teoria institucionalista de John Meyer e Brian Rowan (1977), que possibilita compreender como demandas sociais podem ser incorporadas às organizações de forma cerimonial, sem conflitar com suas práticas tradicionais, atualizando, para o contexto estudado, as noções de disjunção e falta de confiança, que serão posteriormente apresentadas.

Como será desenvolvido no decorrer desse artigo, um tal contexto acaba por fomentar o que os agentes chamam de falta de fechamento, categoria nativa que destaca a falta de união, de confiança e apoio das demais equipes, acusação que é destinada sobretudo à equipe técnica (formada por psicólogos, assistentes sociais e outros profissionais responsáveis pelos atendimentos individuais e familiares, visita em domicílio, produção de relatórios técnicos etc.). Um exemplo desta desconfiança pode ser ilustrada no excerto abaixo:

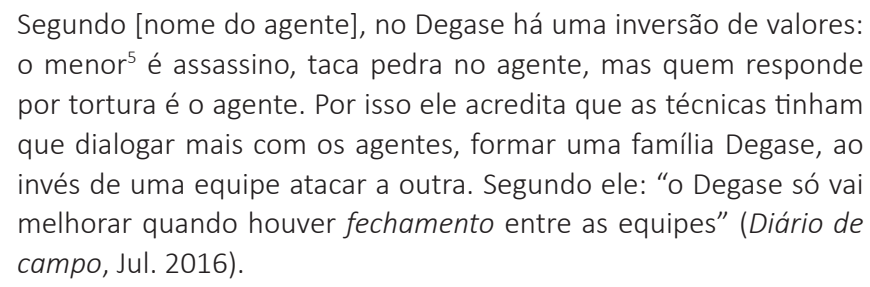

Aqui vemos um agente que almeja maior proximidade entre as diferentes equipes, com especial destaque para a equipe técnica, que, segundo o mesmo, recriminariam os agentes quando os adolescentes os acusam de tortura, maus tratos ou outros tipos de violência. Nesse sentido, o fechamento entre as diferentes equipes proporcionaria maior proteção aos agentes, que, usualmente, são os acusados quando há denúncias contra o Degase (Meireles, 2017). A construção de uma Família Degase é vista como redução de danos em um ambiente acusatório em que as disputas sobre o que é chamado de falta de fechamento ocupa lugar central na maneira como as diferentes equipes se definem entre si.

Neste artigo, analisaremos a maneira como a falta de fechamento é considerada pelos agentes de segurança socioeducativa, a fim de demonstrar que a desconfiança e a disjunção entre diferentes equipes norteiam os trabalhos realizados em um centro de internação e produzem, conjuntamente, a centralidade destinada aos procedi- 
mentos de segurança em detrimento de atividades socioeducativas. Para a construção desse argumento, o artigo está dividido em três seções, além desta introdução e das conclusões finais. Na seção seguinte apresentaremos algumas considerações metodológicas sobre as experiências de pesquisa das autoras para, na sequência, descrever com mais detalhes o que os agentes chamam de falta de fechamento, a fim de destacar como este termo sintetiza alguns conflitos que atravessam a relação entre diferentes servidores que atuam em um cento de internação. Para caracterizar esses conflitos, descreveremos, na seção seguinte, algumas disputas em torno do que chamamos de "poder de produção do relatório". Essa descrição revelará como a equipe dirigente ${ }^{6}$ do Degase administra esses conflitos profissionais, de modo a produzir uma imagem institucional alinhada à socioeducação, ainda que internamente seja a segurança o principal objetivo buscado. Por fim, analisaremos teoricamente como a falta de fechamento produz e é, ao mesmo tempo, produto de um contexto de disjunção e de desconfiança entre as diferentes equipes, o que revelará como conflitos profissionais cotidianos em um centro de internação acabam por legitimar a centralidade que os procedimentos de segurança recebem. Desse modo, ao ser possível atuar de modo desassociado e sem diálogo, as diferentes equipes se orientam com base em seus próprios critérios de eficiência, o que, no caso de grande parte dos agentes de segurança socioeducativa, significa marginalizar atividades socioeducativas em prol da ordem, do controle e da disciplina.

\section{Discussões metodológicas}

As discussões propostas neste artigo decorrem principalmente da pesquisa de tese de doutorado em sociologia realizada por Juliana Vinuto (2020) ${ }^{7}$. Trata-se de uma pesquisa de campo realizada entre 2016 e 2019 em duas unidades de internação do Degase, sendo uma masculina e outra feminina, cujo objetivo foi o de compreender como os agentes de segurança socioeducativa se localizavam em um contexto atravessado por dois objetivos considerados por eles próprios como contraditórios: a segurança e a socioeducação. Durante a pesquisa, os seguintes materiais foram analisados: entrevistas semiestruturadas com agentes de segurança socioeducativa; materiais bibliográficos e institucionais produzidos pelo e sobre o Degase; materiais disponibilizados em sites e redes sociais do Degase e do Sind-Degase; materiais jornalísticos sobre o Degase; diários de campo compartilhados pelo Projeto Parcerias ${ }^{8}$, eventos e cursos oferecidos pelo Degase aos seus profissionais; conversas informais com agentes de segurança socioeducativa; e eventos organizados pelo Poder Judiciário e pelo Poder Legislativo sobre o Degase.

Este artigo também se valeu dos debates na sociologia das organizações que Joana Domingues Vargas vem realizando ultimamente (Vargas \& Rodrigues, 2011). Tais
6. Utilizamos a expressão "equipe dirigente" para nos referir ao grupo responsável pela direção e administração do Degase. Essa expressão toma por base o argumento de Erving Goffman (2010: 69-70), que afirma que em instituições totais há uma divisão básica entre internados e equipe dirigente. Como afirma o autor "Independentemente do que as organizações fazem na prática, elas se apresentam ao público como organizações racionais, conscientemente planejadas como máquinas eficientes para atingir determinadas finalidades oficialmente confessadas e aprovadas. Já se sugeriu também que um frequente objetivo oficial é a reforma dos internados na direção de algum padrão ideal. Esta contradição, entre o que a instituição realmente faz e aquilo que oficialmente deve dizer que faz, constitui o contexto básico da atividade diária da equipe dirigente".

7. Trata-se de uma pesquisa de doutorado em sociologia que foi orientada por Joana Domingues Vargas e coorientada por Hebe Signorini Gonçalves, coautoras 
do presente trabalho.

8. Trata-se de um projeto de extensão universitária coordenado por Hebe Signorini Gonçalves (Instituto de Psicologia da UFRJ), no qual estudantes realizavam visitas a uma unidade do Degase e participavam de reuniões semanais de supervisão, nas quais debatiam diários de campo previamente compartilhados. Ver Leandro Abreo (2017) e Graziela Sereno (2015).

\section{9. É importante} destacar que este artigo tem como foco as narrativas construídas especificamente pelos agentes de segurança socioeducativa, mas é digno de nota que em nossas experiências de pesquisa não identificamos a relevância da falta de fechamento dos discursos para as demais equipes que atuam em centros de internação. trabalhos, somados às suas pesquisas sobre o tratamento direcionado à delinquência juvenil no Brasil (Vargas, 2012), algumas vezes amparadas em análises comparativas com a França (Marinho \& Vargas, 2015), foram de fundamental importância para as discussões empreendidas. Somado a isso, as pesquisas de Hebe Signorini Gonçalves (2016) sobre o sistema socioeducativo carioca também ampararam os debates aqui realizados. O diálogo com sua experiência de pesquisa e extensão no próprio Degase (Gonçalves, Sereno \& Abreo, 2017), incluindo a realização de trabalhos sobre agentes de segurança socioeducativa (Vinuto, Abreo \& Gonçalves, 2017), foi de grande relevância para a discussão ora proposta.

Dessa forma, é o diálogo entre as diferentes experiências de pesquisa que pauta a escrita desse artigo. A articulação entre diferentes áreas, trajetórias, métodos e entradas de campo permitiram complexificar o que foi acessado durante a pesquisa. Por conta disso, o trabalho aqui desenvolvido se orienta mais pela análise dos conflitos e das disputas do que pela busca de uniformidade nos dados empíricos. Ao renunciar à busca pela regularidade foi possível ir além do protesto sobre os "problemas de implementação" do ECA (Lemos \& Bicalho, 2017) e compreender que aquilo que não se ajusta ao que é concebido como a estrutura formal e oficial do Degase não é apenas uma idiossincrasia, mas parte constitutiva da organização (Almeida, 2016; Bittner, 2013; Vargas, 2004; Vargas \& Rodrigues, 2011). Como afirma Hebe Signorini Gonçalves:

\begin{abstract}
A lei, no entanto, não opera como instrumento solitário ou soberano. As normas que ela instaura interagem com as instituições, com as práticas sociais, com o conjunto de fatos concretos que tem lugar na sociedade. O sujeito toma a lei como norma, mas orienta sua conduta também com base naquilo que percebe e vive, nos fatos que presencia, nas ocorrências concretas que conhece ou sofre (Gonçalves 2005: 39).
\end{abstract}

Nas seções seguintes iremos descrever a maneira como a relação entre os diferentes profissionais do Degase é atravessada pela disjunção entre diferentes equipes e pela desconfiança. Assim, se em todas as profissões há uma dimensão de competitividade nas interações entre seus membros (Bonneli, 1998), é necessário pensar quais os efeitos específicos que as disputas entre profissionais atuantes na medida socioeducativa de internação acarretam o atendimento destinado ao adolescente internado. Para tanto, descreveremos as peculiaridades e diferenças na mobilização da noção de falta de fechamento por parte dos agentes de segurança socioeducativa do Degase ${ }^{9}$. Posteriormente, tomamos essas narrativas sobre falta de fechamento como dispositivo relevante para compreender a disjunção e a desconfiança que pautam as relações profissionais no espaço socioeducativo. Por sua 
vez, a disjunção entre diferentes equipes e a desconfiança mútua fomentam uma maneira naturalizada de olhar o imperativo da segurança, cuja centralidade é vista como se fosse incontornável em um centro de internação.

\section{"Fica tudo nas costas do agente" ${ }^{10}$ : a relação entre os diferentes servidores do Degase}

Então o fechamento é isso, você tem que ser fechamento, não que você vá se fechar em grupos para se proteger, corporativismo, não, não nesse sentido. Fechamento no sentido que você tem um sentido só a ser seguido, e todos seguem aquilo. Aí vai, uma diretriz, um caminho, esse troço todo. Então todo mundo tem que estar no fechamento, corpo técnico, direção, coordenação geral, coordenação de plantão, e os integrantes do plantão propriamente dito (Entrevista, agente de segurança socioeducativo masculino, Jun. 2016).

É comum ouvir dos agentes de segurança socioeducativa que o trabalho desenvolvido em um centro de internação depende da confiança uns nos outros. Consta do trecho de entrevista que abre esta sessão que o fechamento se refere à união de todos os profissionais no que diz respeito à implementação de um objetivo comum. Entretanto, a ideia de fechamento demanda usualmente a convergência de discursos e atitudes com relação ao adolescente ou a grupos externos ao espaço socioeducativo, mesmo que isso raramente seja assumido. Trata-se de uma demanda destacada a todo momento justamente em razão de sua inexistência: ocorrem constantes reclamações sobre falta de fechamento, principalmente em relação a recriminações e críticas sobre o trabalho do agente de segurança socioeducativa.

A ideia de falta de fechamento costuma ser apresentada pelos agentes como uma situação efetiva que prejudica o trabalho. Os agentes de segurança socioeducativa ao constatarem a falta de fechamento afirmam que são eles os que mais são prejudicados por essa privação e, por isso, seriam os únicos que realmente se importariam com a discussão sobre o tema. Apesar de ser considerado um termo descritivo, os agentes o mobilizam como modo de acusação, o que revela disputas de significado sobre qual seria o trabalho mais adequado em um centro de internação. Ao levar a sério as afirmações sobre falta de fechamento colocadas pelos agentes, consideramos que, mais importante do que investigar a veracidade de tal constatação, é compreender como esta revela conflitos profissionais que são centrais para a análise da rotina de trabalho em centros de internação do Rio de Janeiro. Deste modo, ao analisar narrativas sobre a existência de falta de fechamento, estamos analisando o modo como a sanção a adolescentes é implementada.
10. Afirmação feita por vários agentes durante pesquisa de campo. 
Como é o servidor que mais interage com o adolescente internado, sendo também o único responsável por sua contenção e disciplina, o agente é o trabalhador com maior possibilidade de se envolver em conflitos. Uma reclamação constante é que apesar de todos os servidores do Degase se beneficiarem do trabalho de segurança feito pelos agentes, a grande maioria acredita incondicionalmente na versão do adolescente quando acusa o agente, independentemente das provas apresentadas. Por isso, o fechamento seria tão importante na rotina de trabalho destes profissionais, pois a confiança dos demais atores do espaço socioeducativo compensaria a vulnerabilidade própria de sua função. Em outras palavras, como consta do título desta seção, grande parte dos agentes acredita que tanto o trabalho mais fastidioso quanto as acusações sempre caem nas costas do agente, mas os demais profissionais não estão dispostos a apoiarem integralmente suas ações.

A falta de fechamento é percebida como algo factual pelos agentes de segurança socioeducativa, mas revela uma situação de conflito no qual estes disputam o significado desse termo nativo para legitimar algumas práticas, regras e saberes específicos. Isso ocorre ainda entre diferentes perfis de agentes: como a presença destes nos centros de internação ocorre de modo intermitente, há a organização de diferentes plantões, sendo que alguns entrevistados afirmam que há incerteza até mesmo sobre o comportamento de agentes desses diferentes plantões. Apesar das demandas comuns que são colocadas diariamente, cada plantão é formado por profissionais diferentes e, portanto, tem características próprias no desenvolvimento dos trabalhos diários. Dessa forma, há plantões considerados mais abertos ao diálogo com os adolescentes, enquanto outros seriam mais rígidos na interação com eles. Como destaca Leandro Abreo:

Cabe ressaltar que tais micropenalidades são altamente discricionárias nas unidades de internação, uma vez que a escolha de uma ou outra sanção dependerá do plantão na unidade, do agente, do dia e do adolescente (Abreo, 2017: 29).

Segundo os agentes, essas distintas formas de atuação possibilitam ao adolescente manejar essas diferenças a seu favor, o que é visto como inconveniente. Assim, os adolescentes fazem diferentes demandas argumentando que "foram autorizadas no outro plantão", mesmo que isso não tenha acontecido de fato. Essa maneira de o adolescente manejar os contrastes entre plantões causa acusações e conflitos entre os próprios agentes e fomenta discursos que almejam deslegitimar os plantões julgados como excessivamente tolerantes.

Entretanto, os conflitos existentes entre diferentes grupos de agentes não são mais fortes do que sua solidariedade quando são criticados por grupos como os exter- 
nos. Há uma crença de que apenas um agente entende os dilemas vividos por outro agente, o que cria um ambiente de compreensão, mesmo que não completamente franco. Egon Bittner (2017) trata deste ponto em suas pesquisas sobre a instituição policial, demonstrando efeitos agregadores na relação com membros externos ao grupo. Quando há acusações contra um agente é comum que os demais prefiram se abster de opinar ou justifiquem o comportamento do mesmo. Essa união é uma característica relevante em outras profissões relacionadas com a segurança, como pontua Bittner (2017) em relação à organização policial:

\begin{abstract}
Aqueles que são profissionais totalmente competentes não esperam criar relações amigáveis com seus pares, mas esperam, de fato, e recebem grande e irrestrito apoio em situações de perigo físico ou quando sob ataque vindo de pessoas de fora. Isto é, dentro da instituição, os policiais se esforçam para ficar fora do caminho um do outro, mas no mundo externo, eles mantêm uma frente marcadamente unificada (Bittner, 2017: 35-36).
\end{abstract}

Essa postura de lealdade com relação às acusações externas é vista como proteção contra a falta de fechamento que existiria entre os diferentes servidores do Degase. Os outros profissionais, em especial os da equipe técnica, são vistos como aqueles que não demonstram o mesmo apoio incondicional, e por isso são acusados por presumivelmente acreditarem de maneira precipitada nas versões de conflitos relatadas pelos adolescentes ${ }^{11}$. Produz-se, assim, um ambiente acusatório a partir de estereótipos hostis construídos por ambas as partes, em que grande parte dos integrantes da equipe técnica considera os agentes excessivamente agressivos, ao mesmo tempo em que estes afirmam que os primeiros costumam ser excessivamente condescendentes com os adolescentes internados:

O não "fechamento" representa a discordância entre agentes e técnicos quanto ao tratamento conferido aos adolescentes, especialmente quando estes burlam alguma norma ou desobedecem às regras. Os técnicos, lançando mão do Estatuto da Criança e do Adolescente e das teorias acerca da natureza do adolescente, condenam as práticas que, para eles, são punição exagerada ou violência contra os jovens. Os agentes, por sua vez, trabalham seguindo as determinações dos poderes Judiciário e Executivo, guiando-se por uma lei (5.933/2011) que precede as suas práticas, encarando como imposição da disciplina o que os técnicos nomeiam como violência. O "não fechamento" expressa a discordância não apenas sobre as formas de trabalhar e lidar com os adolescentes em conflito com a lei, mas também sobre a natureza do "ser adolescente" (Silva, 2013: 139).

Apesar de os agentes de segurança socioeducativa imputarem a culpa pela falta de fechamento a diferentes instâncias, é a equipe técnica a principal acusada, sobretu-
11. Sobre as relações entre equipe técnica e agentes penitenciários nas prisões para adultos, ver Pedro Bodê de Moraes (2005). 
do porque não legitimaria incondicionalmente suas práticas. Desse modo, a falta de fechamento é vista como responsável por relações distanciadas, muitas vezes até por rivalidades, sendo raros os centros de internação em que as diferentes equipes mantêm relações completamente cordiais. Claro que há alguns casos em que um ou outro profissional se relaciona bem com integrantes de outras equipes, mas são exceções que confirmam a regra.

Nessa direção, as reclamações sobre falta de fechamento entre diferentes equipes, colocadas pelos agentes de segurança socioeducativa, refletem disputas de poder nas quais há um esforço para demonstrar quem conhece verdadeiramente o adolescente internado. Os agentes alegam que, por interagirem com o adolescente durante toda sua jornada de trabalho, teriam mais elementos para conhecer sua essência, ao contrário da equipe técnica, que seria facilmente enganada por supostamente realizar apenas atendimentos pontuais. Esse argumento torna-se factível devido à crença de que é mais fácil simular um comportamento circunscrito durante $o$ atendimento localizado com a equipe técnica do que interpretar um papel durante todos os momentos em que estão interagindo com os agentes. Nessa direção, os agentes de segurança socioeducativa veem uma disputa entre um saber avaliado pejorativamente como teórico e seu próprio saber, enunciado como saber prático.

O relatório psicossocial é um elemento relevante para conhecer as rivalidades em torno da legitimidade de cada uma dessas equipes, pois se revela enquanto concretização dessas disputas de saber-poder. Esse documento é construído pela equipe técnica a partir de informações sobre o comportamento do adolescente, bem como de sua família (Vinuto \& Alvarez, 2018), a fim de ser enviado ao Judiciário no máximo a cada seis meses para subsidiar o juiz com informações para a tomada de decisão sobre a continuidade, a progressão ou a regressão da medida socioeducativa. Por um lado, o adolescente encarcerado enche-se de esperança a cada relatório produzido, já que se renovam as possibilidades de obter a liberdade; por outro, neste documento também são encontradas implícitas as justificativas que reforçam a necessidade do trabalho da própria instituição (Almeida, 2016). Nesse contexto, os agentes se sentem injustiçados por não serem consultados durante a produção do documento, como veremos a seguir.

12. Afirmação proferida por vários agentes durante a pesquisa de campo.
"O que os adolescentes fazem com as técnicas é teatro"12: disputas em torno do poder de produção do relatório.

Vamos supor que o adolescente fique uma hora com a técnica. As outras 23 horas ele fica comigo. Quem você acha que conhece melhor aquele adolescente? O relatório tem que ser feito de três em três meses. Com a superlotação, pensa quantas vezes dá para 
atender cada menino. Se tudo corresse perfeitamente, ele seria atendido três vezes nesses três meses. Mas o que acontece é que muitas vezes ele só é atendido uma vez (Diário de campo do Projeto Parcerias, Centro de Internação Masculino, Out. 2015).
Segundo o Capítulo IV, Seção VII, § 2o do ECA, a "medida [socioeducativa] não comporta prazo determinado, devendo sua manutenção ser reavaliada, mediante decisão fundamentada no máximo a cada seis meses". Essa reavaliação ocorre principalmente a partir do relatório psicossocial - ou apenas relatório, como usualmente é nomeado -, que é um documento produzido pela equipe técnica ${ }^{13}$ sobre o adolescente internado e enviado ao Poder Judiciário para a avaliação sobre as possibilidades de manter, alterar ou encerrar a medida socioeducativa que está sendo cumprida. Nesse sentido, o envio do relatório ao Poder Judiciário é acompanhado de grande ansiedade por parte dos adolescentes, que podem ou não ser desinternados a depender da recepção do mesmo. Ao mesmo tempo, muitos agentes de segurança socioeducativa criticam o fato de esse documento, tão central para a vida do adolescente, ser produzido sem consultá-los. Essa insatisfação ocorre porque creem que a equipe técnica detém um conhecimento limitado sobre o adolescente e por isso seriam permissivos com o mesmo.

Esse contexto torna o relatório um documento central em torno do qual ocorrem muitas disputas. É por essa razão que os agentes afirmam que os adolescentes fazem teatro para as técnicas, interpretando estarem arrependidos por seus erros e prontos para se afastarem do "mundo do crime"14, prometendo estudar, trabalhar e ajudar sua família. Há uma crença de que a equipe técnica acredita incondicionalmente nessa presumida interpretação e isso afetaria a qualidade do relatório produzido. Por isso, muitos agentes definem a equipe técnica como crédula e ingênua, e o relatório produzido como um documento distante da realidade (Gonçalves, Sereno \& Abreo, 2018).

Contudo, não é apenas a suposta ingenuidade da equipe técnica que justifica o sentimento de injustiça no que se refere à não participação dos agentes na produção do relatório. Ocorre que, ao serem excluídos da produção desse documento, os agentes entendem que a instituição não considera o saber específico desse grupo profissional, o saber prático. Tal ambiente fomenta disputas sobre quem tem o saber mais legítimo sobre o adolescente, quem será a equipe técnica a receber a chancela por parte da equipe dirigente do Degase para produzir o documento oficial a ser enviado ao Poder Judiciário. O fato de não serem ouvidos durante o processo de construção do relatório, e por conseguinte pelo Poder Judiciário, dá aos agentes a sensação de que seu saber prático é dispensável e menos válido do que o saber que eles nomeiam como teórico e ingênuo, sugerindo o desprestígio de seu trabalho frente ao Degase.
13. Para conhecer outras maneiras de produção do relatório técnico, realizada no sistema socioeducativo paulista, ver Bruna Gisi de Almeida (2016) e Juliana Vinuto (2014)

14. Para um debate sobre o "mundo do crime", ver Gabriel Feltran (2008). 
Nesse contexto, são geradas disputas em torno do que chamamos de "poder de produção do relatório", ou seja, a faculdade e a legitimidade atribuídas a determinados profissionais para classificar, em um documento oficial, o comportamento do adolescente internado fruto de sua intervenção (Vinuto, 2014). Dessa forma, as disputas em torno do poder de produção do relatório materializam os conflitos entre os agentes e a equipe técnica.

As disputas em torno do poder de produção do relatório evidenciam tanto a falta de fechamento entre diferentes equipes profissionais do Degase quanto a deslegitimação que o saber prático dos agentes de segurança socioeducativa enfrenta dentro e fora da instituição. Os agentes sentem que todas as responsabilidades e injustiças da instituição recaem sobre suas costas, mas os trabalhos realizados em proximidade ao adolescente que legitimariam o seu saber prático e que poderiam ser registrados no relatório de modo a embasar as decisões sobre os adolescentes são desautorizados. Sobre isso, Abreo assinala:

Poder opinar e acrescentar no relatório seria o único dispositivo que permitiria dar algum significado oficial para seu trabalho no Degase que tem a expressão "socioeducativo" na nomenclatura do cargo. Este sofrimento é intensificado por perceberem que, em muitos casos, o que aparece no relatório é contraditório com sua experiência e com seu saber sobre o adolescente. É uma situação que, além de acirrar ainda mais os conflitos e o comum distanciamento existente nas instituições totais entre o corpo técnico e o de segurança, renega ou subutiliza a inteligência prática que é desenvolvida por esses profissionais ao longo do intenso e permanente contato com os internos (Abreo, 2017: 120).

A forma pela qual a equipe dirigente do Degase maneja as disputas sobre o poder de produção do relatório pode ser pensada a partir das considerações foucaultianas sobre saber-poder (Foucault, 2007). Michel Foucault analisa como os saberes desqualificados pela ciência hegemônica se tornam discursos periféricos, revelando que a principal estratégia do discurso científico é desqualificar os saberes contemplados como não científicos, inferiores, "insuficientemente elaborados" (Foucault, 2007). Para o autor, o poder produz saber e por isso "não há relação de poder sem constituição correlata de um campo de saber, nem saber que não suponha e não constitua ao mesmo tempo relações de poder" (Foucault, 2007: 27).

Entretanto, apesar das representações que entendem saber teórico e saber prático como opostos, é relevante pensar como o Degase apresenta uma configuração organizacional que utiliza ambos de maneira complementar, a depender do contexto. Hebe Gonçalves, Graziela Sereno e Leandro do Abreo (2017) destacam que as dis- 
putas sobre quem conhece mais o adolescente só são possíveis porque ignoram o quanto o saber teórico e o saber prático se assemelham.

Nesse sentido, as funções dos agentes socioeducativos ${ }^{15}$ - que acompanham o adolescente no seu cotidiano - e dos técnicos - que acessam sua subjetividade por meio de exames consignados nos laudos - não são divorciados. Ao contrário, eles se somam e se potencializam. O fato de se constituírem em saberes diferentes, cada qual com sua lógica própria, não faz com que um necessariamente se sobreponha ao outro (Gonçalves, Sereno \& Abreo, 2017: 123).

Essa complementaridade entre os saberes teórico e prático pode não ser percebida por grande parte dos agentes, mas ela não deixa de ser relevante para a produção cotidiana da obviedade com que são vistos os procedimentos de segurança: internamente, o saber dos agentes socioeducativos é central para a manutenção da ordem e da disciplina, mas frente ao Poder Judiciário é o saber da equipe técnica que será demonstrado como indício de que os objetivos relacionados à socialização estão sendo buscados. Nesse sentido, o saber e as práticas dos agentes são decisivos e funcionais para o funcionamento cotidiano da instituição, ainda que os mesmos não sejam valorizados externamente.

Vale lembrar que há trabalhos que indicam que a ideia de periculosidade também atravessa o trabalho de psicólogos, assistentes sociais, pedagogos e demais integrantes da equipe técnica (Hernanez, 2018; Vinuto, 2014), ressaltando representações sobre o adolescente internado que indicam descrença em suas possibilidades de "ressocialização". Isso significa que os agentes socioeducativos não são os elementos decisivos para a construção de um ambiente seguro no centro de internação, já que o mesmo não decorre exclusivamente das atitudes desses profissionais. Ao contrário, qualquer indivíduo que aí atue será afetado de alguma forma pela lógica da contenção (Vinuto \& Franco, 2019).

Somado a isso, é importante destacar que o debate sobre as relações de oposição entre saberes considerados práticos e aqueles observados como técnicos ou teóricos não é novo, como é ilustrado nas discussões sobre instituições totais (Goffman, 2010). Isso fica particularmente claro nas discussões nacionais sobre instituições de controle e ordem, em especial no caso das polícias (Lima, 1995; Muniz, 2001; Poncioni, 2005; Medeiros, 2021). O que gostaríamos de destacar sobre a atuação dos agentes de segurança socioeducativa em centros de internação do Rio de Janeiro é que essa oposição, vista como autoevidente, compõe a naturalização com que é vista a centralidade dos procedimentos de segurança. É sobre este ponto que nos deteremos a partir de agora.
15. "Agente socioeducativo" é um dos modos como a função de agente de segurança socioeducativo foi nomeada ao longo da história. Para um debate sobre os diferentes termos que foram utilizados para nomear esta função, ver Vinuto (2020). 


\title{
Disjunção e desconfiança: \\ a centralidade dos procedimentos de segurança
}

\begin{abstract}
O agente é excluído de todo o processo... Mas se tiver problema, é o primeiro a ser acionado. O adolescente chega lá e fala a mesma história de sempre para a técnica, mas se ele mandar a técnica tomar no cu e se foder, ela chama o agente (Entrevista de agente de segurança socioeducativa masculino fora do local de trabalho, Fev. 2018).
\end{abstract}

O trecho de entrevista que abre essa seção ilustra como os agentes de segurança socioeducativa se sentem depreciados e excluídos das atividades essenciais referentes às decisões sobre o adolescente, tais como a elaboração do relatório, o planejamento e a organização das atividades socioeducativas ou a construção do Plano Individual de Atendimento (PIA). E, ao mesmo tempo, o referido trecho indica que apesar de os agentes serem excluídos dessas práticas, são peças fundamentais do processo, visto que são rapidamente acionados quando algo sai do controle. Isso sugere que as atividades socioeducativas só podem ser realizadas com o apoio e a segurança afiançada pelos mesmos, sendo este um aspecto importante no cotidiano institucional, na medida em que a própria equipe técnica reconhece a relevância da ação do agente. Atravessada por certo ressentimento, a afirmação acima ilustra a centralidade com que os agentes veem sua própria função de manutenção da ordem em um centro de internação. Desse modo, ainda que esses agentes e técnicos atuem na mesma instituição, não se articulam a partir dos mesmos princípios.

Uma tal constatação vai de encontro à análise organizacional de John Meyer e Brian Rowan (1977), que argumentam que instituições, a partir de seus operadores, não agem baseadas em coordenação e controle rígidos entre estrutura e ações, mas a partir de um "ajustamento frouxo" entre o que é prescrito e o que é de fato realizado, e entre diferentes grupos, departamentos, equipes etc. Esse ajustamento frouxo permite que determinadas ações sejam realizadas apenas com uma vaga coordenação entre as diferentes partes. Para os autores, a disjunção entre a regra e sua aplicação e entre os diferentes grupos profissionais minimiza a existência de conflitos e ainda permite a construção de uma imagem pública adequada ao que é entendido como razoável pela sociedade mais ampla. Meyer e Rowan argumentam ainda que quando a sociedade coloca uma demanda para uma organização, esta se vê pressionada a atendê-la a fim de angariar legitimidade para as suas ações. Desta forma, as instituições incorporam elementos externos já aceitos como importantes em outras organizações para fortalecer sua própria legitimidade, mas usualmente isso ocorre apenas de modo cerimonial. Tal argumentação nos ajuda a compreender como a disjunção no Degase torna-se central para a incorporação cerimonial da 
socioeducação. No caso do Degase, o âmbito socioeducativo, presente nas regras, documentos e discursos oficiais, é apresentado como central pela instituição, mas não integra efetivamente as práticas cotidianas de trabalho com os adolescentes, sendo mobilizado apenas de modo protocolar a fim de justificar e legitimar externamente a existência da instituição.

\begin{abstract}
Nas sociedades modernas, os elementos da estrutura formal racionalizada estão profundamente enraizados e refletem compreensões generalizadas da realidade social. Muitos dos cargos, das políticas, dos programas e dos procedimentos das organizações modernas são compelidos pela opinião pública, pelos pontos de vista dos importantes eleitores, pelo conhecimento legitimado através do sistema educacional, pelo prestígio social, pelas leis e pelas definições de negligência e prudência usadas pelos tribunais. Tais elementos da estrutura formal são manifestações de poderosas regras institucionais que funcionam como mitos altamente racionalizados que são obrigatórios para organizações particulares (Meyer \& Rowan, 1977: 343, tradução livre).
\end{abstract}

Meyer e Rowan entendem tais demandas sociais externas como "mitos" que as instituições dizem seguir, mas que são efetivamente pouco realizáveis. As organizações que afirmam incorporar esses mitos difundidos na sociedade "aumentam sua legitimidade e suas perspectivas de sobrevivência, independentemente da eficácia imediata das práticas e procedimentos adquiridos" (Meyer \& Rowan, 1977: 340, tradução livre). Quando os membros da organização entendem que tais mitos conflitam com o que consideram ser mais eficiente para seus objetivos diários, acabam por incorporá-los apenas de maneira cerimonial, e não de forma a alterar a estrutura institucional. Isto é, as pessoas afirmam se conformar com esses mitos para que possam continuar com o seu trabalho cotidiano, usando os procedimentos usuais sem serem importunadas.

Observa-se até aqui que a incorporação da socioeducação no Degase ocorre de maneira cerimonial, e assim a própria instituição pode mostrar à sociedade que atende às suas demandas de "ressocialização" do adolescente internado, mas sem incorporá-las à rotina da instituição. Aqui vemos qual a lógica que efetivamente rege essa instituição: o controle e a disciplina dos adolescentes, visto que as atividades de caráter educativo só são admitidas quando não são vistas como riscos à segurança da instituição. Como a equipe dirigente do Degase não pode se opor abertamente às normativas e suprimir as iniciativas socioeducativas, a incorporação cerimonial da socioeducação se revela politicamente estratégica, pois pode ser manejada enquanto prova da realização dos objetivos legais existentes. Assim, a equipe dirigente da instituição preserva o mito do atendimento humanizado ao 
mesmo tempo em que constrói sua própria legitimidade atuando, sobretudo, no controle dos adolescentes e na minimização de fugas e conflitos.

Para Meyer e Rowan, as tensões entre as regras - implementadas apenas de modo cerimonial - e as práticas - aquelas consideradas adequadas e razoáveis pelos profissionais que atuam na instituição - são minimizadas a partir de duas estratégias articuladas: a disjunção entre grupos que se colocam objetivos diversos, o que diminui o número de conflitos; e as manifestações de confiança e de boa-fé entre esses grupos, que confiam na previsibilidade das ações dos demais. Ambas as estratégias evitam inspeções de um grupo sobre outro, o que ajuda a construir a legitimidade da organização.

Como vimos, a disjunção entre diferentes equipes, ilustrada nas acusações de falta de fechamento, pauta grande parte das relações entre os profissionais que atuam no espaço socioeducativo. Mas de modo oposto ao que foi pensado por Meyer e Rowan, não só ela engendra a origem das acusações, como também sua presença não é acompanhada de manifestações de confiança e de boa-fé. Ao contrário, como arrolamos ao longo do artigo, a falta de fechamento implica em desconfiança. Essa situação também foi observada em outras pesquisas sobre organizações de controle brasileiras, como no trabalho de Joana Vargas e Juliana Rodrigues (2011) sobre a disjunção entre diferentes instituições do sistema de justiça. As autoras afirmam:

\footnotetext{
O que, ao nosso ver, é particular ao Brasil e destoante do esquema proposto pela teoria das organizações (TO) é o fato de a disjunção não ser acompanhada de manifestações de confiança e boa-fé. Muito pelo contrário, prevalece em nosso sistema a desconfiança entre os operadores responsáveis por administrar a Justiça (Vargas \& Rodrigues, 2011: 81).
}

Vargas e Rodrigues destacam que a desigualdade entre diferentes grupos profissionais ajuda a explicar esse ambiente de desconfiança, dadas as disputas entre saberes considerados mais legítimos do que outros. Se levarmos a sério as considerações dos agentes de segurança socioeducativa sobre a existência de falta de fechamento, podemos pensar que, se, por um lado, a disjunção entre agentes e equipe técnica minimiza os conflitos na realização das atividades cotidianas, por outro produz um ambiente acusatório entre as partes na qual o que prevalece é a desconfiança generalizada. Assim, o Degase funciona a partir de um "ajustamento frouxo" (Meyer \& Rowan, 1977: 341) entre suas diferentes instâncias, o que permite que profissionais com crenças diversas sobre a natureza de seu trabalho convivam na mesma instituição. Isso fomenta também o predomínio do imperativo da segurança, já que aqueles que estão alinhados com o discurso de controle, ordem 
e disciplina não precisam prestar contas ao renunciar aos objetivos socioeducativos oficiais. Pelo contrário, são percebidos como essenciais à instituição porque resolvem problemas práticos do cotidiano.

Assim, se diferentes profissionais divergem sobre o que deveria ser o seu próprio trabalho - segurança ou socioeducação, usualmente vistos de maneira mutuamente excludente (Vinuto, 2020; Vinuto, Abreo \& Gonçalves, 2017) - a disjunção entre diferentes equipes minimiza a existência de conflitos abertos e coletivamente organizados, já que cada grupo profissional pode atuar sem ser importunado pelos demais. E assim há uma justificativa avaliada como razoável - a falta de fechamento - para não entrarem em harmonia sobre o que deveria ser a medida socioeducativa de internação.

Se Georg Simmel (2011) já destacou que qualquer forma social, por mais homogênea que pareça, é calcada em conflitos recorrentes, é possível ainda ampliar o significado da falta de fechamento no contexto socioeducativo, ao entendê-la como parte integrante da própria positividade do Degase. Os conflitos cotidianos são invisíveis ao público externo e não transformam a instituição porque não ganham amplitude, sendo resolvidos local e individualmente. Mesmo assim, têm consequências para a legitimidade do Degase enquanto instituição, já que na prática cotidiana há a prevalência da lógica da segurança, ainda que isso não apareça nos discursos oficiais. Neste ínterim, ao grupo de agentes socioeducativos alinhados à garantia de direitos, resta uma atuação individual nas brechas que os condena a um sentimento permanente de constituírem exceções (Vinuto, 2020).

As considerações colocadas até aqui podem contribuir com o debate sobre as singularidades das medidas socioeducativas. Muitos trabalhos relevantes já discutiram a importância política da implementação de sanções específicas aplicadas a adolescentes (Paula, 2011; Rizzini \& Pilotti, 2011; Schuch, 2005; Vicentin, 2005). Ao mesmo tempo, grande parte desses mesmos trabalhos demonstram o quanto a letra da lei está distante de sua implementação concreta. O que se propôs neste artigo foi analisar determinados elementos para compreendermos não apenas o desencaixe entre a lei e sua execução, mas sobretudo as razões mobilizadas por alguns atores do sistema socioeducativo quando argumentam que tal desencaixe é incontornável. Assim, se agentes de segurança socioeducativa manejam acusações de falta de fechamento para destacar sua marginalização e justificar seus saberes e práticas no espaço socioeducativo, as análises aqui propostas sobre disjunção e desconfiança nos ajudam a compreender como os mesmos conseguem centralizar procedimentos de segurança sem atentar para a dimensão socioeducativa de sua função. Vemos que, em um mesmo movimento, os agentes destacam que vivem 
uma posição subalterna, mas em seu cotidiano de trabalho são aqueles que dão as cartas do jogo, priorizando modos de atuação que focam em disciplina, lei e controle.

\section{Considerações finais}

A análise sobre a categoria nativa falta de fechamento, mobilizada por agentes de segurança socioeducativa que atuam em centros de internação do Rio de Janeiro, permitiu-nos compreender como, apesar de ser vista como expressão simplesmente descritiva, ela implica disputas de significado sobre o que seria o trabalho adequado a ser feito em um centro de internação. Essa categoria permitiu-nos mostrar como a disjunção entre diferentes equipes e a desconfiança que pauta as relações entre profissionais no espaço socioeducativo produzem e, ao mesmo tempo, são produtos de um contexto organizacional no qual os procedimentos de segurança são centrais enquanto a socioeducação é vista como prescindível. Afirmamos que as acusações de falta de fechamento "produz" disjunção e desconfiança porque sua invocação reproduz uma lógica em que as diferentes equipes são vistas de modo essencialista e em oposição entre si; ao mesmo tempo, a falta de fechamento é "produto" de um contexto organizacional que não incentiva o trabalho conjunto entre diferentes equipes profissionais e, desse modo, permite que cada grupo utilize seus próprios critérios de eficiência em sua jornada de trabalho.

Ao permitir que diferentes equipes profissionais não interajam apropriadamente, a equipe dirigente do Degase ajuda a construir um contexto organizacional no qual cada grupo pode fazer o trabalho do modo que considera mais apropriado, sem necessariamente prestar conta um ao outro. Isso faz com que aqueles profissionais que não se adaptam aos objetivos socioeducativos possam atuar de maneira dissociada dos discursos oficiais e nem sempre sejam responsabilizados por isso. Às atividades educativas se reserva um papel cerimonial, já que essas são implementadas apenas em situações que não conflitam com os objetivos de controle e disciplina ou em ocasiões em que a equipe dirigente da instituição deseja auferir algum lucro simbólico ao adotar a perspectiva socioeducativa.

Nossa análise sobre a disjunção entre diferentes equipes revela que esta não elimina as disputas e a desconfiança entre profissionais que se alinham de modos diversos em sua jornada de trabalho. Ao contrário, desnuda a persistência desses conflitos decorrentes do modo desigual como os saberes profissionais são considerados, o que é sintetizado nas disputas em torno do poder de produção do relatório, peça que justifica e projeta o trabalho realizado pela instituição para o público externo. E ao administrar essa desigualdade, de modo a endossar uma lógica da 
segurança interna ao mesmo tempo em que projeta uma imagem externa alinhada à socioeducação, a equipe dirigente do Degase não harmoniza a racionalidade própria a cada grupo profissional, ao contrário, contribui ativamente para produzir a prescindibilidade da socioeducação dentro de seus muros.

\section{Referências}

ABREO, Leandro. Entre capturas e resistências: situações de saúde e adoecimento no trabalho de agentes socioeducativos. Dissertação (Mestrado em Psicologia) Instituto de Psicologia, Universidade Federal do Rio de Janeiro, Rio de Janeiro, 2017.

ALMEIDA, Bruna Gisi M. de. A racionalidade prática do isolamento institucional: um estudo da execução da medida socioeducativa de internação em São Paulo. Tese (Doutorado em Sociologia). Faculdade de Filosofia, Letras e Ciências Humanas, Universidade de São Paulo, São Paulo, 2016.

A experiência da internação entre adolescentes: práticas punitivas e rotinas institucionais. Dissertação (Mestrado em Sociologia). Faculdade de Filosofia, Letras e Ciências Humanas, Universidade de São Paulo, São Paulo, 2010.

BATISTA, Vera Malaguti. Adeus às ilusões "re". In: COIMBRA, Cecília Maria B.; AYRES, Lígia Santa Maria; NASCIMENTO, Maria Lívia do (Eds.). Pivetes: encontros entre a psicologia e o Judiciário, p. 195-199. Curitiba: Juruá Editora, 2009.

BAYLEY, Davis. Padrões de policiamento. São Paulo: Editora USP, 2001.

BITTNER, Egon. Aspectos do trabalho policial. São Paulo: Editora USP, 2017.

. The concept of organization. Ethnographic Studies, v. 13, p. 175-187, 2013.

BONELLI, Maria da Gloria. A competição profissional no mundo do Direito. Tempo social, v. 10, n. 1, p. 185-214, 1998.

BRASIL. Sistema Nacional de Atendimento Socioeducativo (Sinase), Lei 12.594, de 18 de janeiro de 2012.

Estatuto da Criança e do Adolescente (ECA), Lei 8.069, de 13 de julho de 1990.

FELTRAN, Gabriel de S. Fronteiras de tensão: um estudo sobre política e violência nas periferias de São Paulo. Tese (Doutorado) - Instituto de Filosofia e Ciências Humanas, Universidade Estadual de Campinas, Campinas, São Paulo, 2008. 
FOUCAULT, Michel. Vigiar e punir: nascimento da prisão. Petrópolis, RJ: Vozes, 2007. GOFFMAN, Erving. Manicômios, prisões e conventos. São Paulo: Perspectiva, 2010. GONÇALVES, Hebe S. Sobre a morte, sobre a vida: a produção da bíos em adolescentes em conflito com a lei. Revista Polis e Psique, v. 6, n. 1, p. 65-84, 2016.

Medidas socioeducativas: avanços e retrocessos no trato do adolescente autor de ato infracional. In: ZAMORA, Maria Helena. Para além das grades: elementos para a transformação do sistema socioeducativo. Rio de Janeiro; São Paulo: Editora PUC-Rio; Loyola, 2005.

GONÇALVES, Hebe S.; SERENO, Graziela C.; ABREO, Leandro de O. O fazer socioeducativo: trabalhando com os agentes. In: ZAMORA, Maria Helena; OLIVEIRA, Maria Cláudia (Orgs.). Perspectivas interdisciplinares sobre adolescência, socioeducação e direitos humanos, p. 202-220. Curitiba: Appris, 2017.

HERNANDEZ, Jimena de G. O Adolescente dobrado: cartografia feminista de uma unidade masculina do Sistema Socioeducativo do Rio de Janeiro. Tese (Doutorado em Psicologia) - Instituto de Psicologia, Universidade Estadual do Rio de Janeiro, Rio de Janeiro, Rio de Janeiro, 2018.

LEMOS, Flavia S.; BICALHO, Pedro Paulo. A circunscrição histórica das políticas de enfrentamento ao ato infracional e a crítica do adolescente. In: ZAMORA, Maria Helena; OLIVEIRA, Maria Cláudia (Orgs.). Adolescência, socioeducação e direitos humanos. Curitiba: Appris, 2017.

LIMA, Roberto Kant de. A polícia da cidade do Rio de Janeiro: seus dilemas e paradoxos. Rio de Janeiro: Forense, 1995.

MARINHO, Frederico C.; VARGAS, Joana D. Permanências e resistências: legislação, gestão e tratamento da delinquência juvenil no Brasil e na França. Dilemas: Revista de Estudos de Conflito e Controle Social, v. 1, p. 267-298, 2015.

MEDEIROS, Flavia. Linhas de investigação: uma etnografia das técnicas e moralidades numa divisão de homicídios da Polícia Civil do Rio de Janeiro. Rio de Janeiro: Autografia, 2021

MEIRELES, Camila de C. Entre a educação e a disciplina: sobre agentes socioeducativos do Estado do Rio de Janeiro. Dissertação (Mestrado em Sociologia) - Pontifícia Universidade Católica do Rio de Janeiro, Rio de Janeiro, Rio de Janeiro, 2017.

MEYER, John W.; ROWAN, Brian. Institutionalized organizations: formal structure as myth and ceremony. American Journal of Sociology, v. 83, n. 2, p. 340-363, 1977. 
MORAES, Pedro R. Bodê de. Punição, encarceramento e construção de identidade profissional entre agentes penitenciários. São Paulo: IBCCrim, 2005.

MUNIZ, Jacqueline de Oliveira et al. A crise de identidade das polícia militares brasileiras: dilemas e paradoxos da formação educacional. Security and Defense Studies Review, v. 1, p. 187-198, 2001.

PAULA, Liana de. Liberdade assistida: punição e cidadania na cidade de São Paulo. Tese (Doutorado em Sociologia) - Programa de Pós-Graduação em Sociologia, Faculdade de Filosofia, Letras e Ciências Humanas, Universidade de São Paulo, São Paulo, 2011.

PONCIONI, Paula. O modelo policial profissional e a formação profissional do futuro policial nas academias de polícia do Estado do Rio de Janeiro. Sociedade e Estado, v. 20, n. 3, p. 585-610, 2005.

RIZZINI, Irene; PILOTTI, Francisco (Orgs.). A arte de governar crianças: a história das políticas sociais, da legislação e da assistência à infância no Brasil. São Paulo: Cortez, 2011.

SANTOS, Erika Piedade da Silva. Desconstruindo a menoridade: a psicologia e a produção da categoria menor. In: GONÇALVES, Hebe Signorini; BRANDÃO, Eduardo Ponte (Orgs.). Psicologia jurídica no Brasil. 3. ed. Rio de Janeiro: NAU, 2014.

SCHUCH, Patrice. Práticas de Justiça: uma etnografia do "Campo de Atenção ao Adolescente Infrator" no Rio Grande do Sul, depois do Estatuto da Criança e do Adolescente. Tese (Doutorado em Antropologia Social) - Programa de Pós-Graduação em Antropologia Social, Instituto de Filosofia e Ciências Humanas, Universidade Federal do Rio Grande do Sul, Porto Alegre, Rio Grande do Sul, 2005.

SERENO, Graziela. Agente socioeducativo: possibilidades e impossibilidades de atuação e formação no território socioeducativo. Dissertação (Mestrado em Psicologia) - Instituto de Psicologia, Universidade Federal do Rio de Janeiro, 2015.

SILVA, Marcia C. S. Nos mundos do Departamento Geral de Ações Socioeducativas: adolescentes, agentes e técnicos nos contextos da administração da justiça para a juventude. Dissertação (Mestrado em Sociologia) - Instituto de Estudos Sociais e Políticos, Universidade do Estado do Rio de Janeiro, Rio de Janeiro, Rio de Janeiro, 2013.

SIMMEL, Georg. O conflito como sociação. Revista Brasileira de Sociologia da Emoção, v. 10, n. 30, p. 568-573, 2011. 
VARGAS, Joana D. Adolescentes infratores no Rio de Janeiro: violência e violação de direitos fundamentais. Revista do Centro de Filosofia e Ciências Humanas, Ano 2, n. 4, p. 26-41, 2012.

Estupro: que justiça? Fluxo do funcionamento e análise do tempo da justiça criminal para o crime de estupro. Rio de Janeiro: Instituto Universitário de Pesquisas do Rio de Janeiro, 2004.

VARGAS, Joana D.; RODRIGUES, Juliana N. L. Controle e cerimônia: o inquérito policial em um sistema de justiça criminal frouxamente ajustado. Sociedade e Estado, v. 26, n. 1, p. 77-96, 2011.

VICENTIN, Maria Cristina G. A vida em rebelião: jovens em conflito com a lei. São Paulo: Hucitec; Fapesp, 2005.

VINUTO, Juliana. "O outro lado da moeda": o trabalho dos agentes socioeducativos no estado do Rio de Janeiro. Rio de Janeiro: Autografia, 2020.

. Entre o "recuperável" e o "estruturado": classificações dos funcionários de medida socioeducativa de internação acerca do adolescente em conflito com a lei. Dissertação (Mestrado em Sociologia) - Programa de Pós-Graduação em Sociologia da Universidade de São Paulo, Universidade de São Paulo, São Paulo, São Paulo, 2014.

VINUTO, Juliana; DUPREZ, Dominique. O duplo objetivo sancionatório-educativo no Brasil e na França: as diferentes configurações organizacionais direcionadas ao adolescente em conflito com a lei. Revista Dilemas, Edição Especial, n. 3, p. 115-135, 2019.

VINUTO, Juliana; FRANCO, Túlio Maia. "Porque isso aqui, queira ou não, é uma cadeia": as instituições híbridas de interface com a prisão. Mediações - Revista de Ciências Sociais, v. 24, n. 2, p. 250-277, 2019.

VINUTO, Juliana; ALVAREZ, Marcos Cesar. O adolescente em conflito com a lei em relatórios institucionais. Pastas e prontuários do "Complexo do Tatuapé" 1 (Febem, São Paulo/SP, 1990-2006). Tempo Social, v. 30, p. 233-257, 2018

VINUTO, Juliana; ABREO, Leandro; GONÇALVES, Hebe S. No fio da navalha: efeitos da masculinidade e virilidade no trabalho de agentes socioeducativos. Plural, v. 24, p. 54-77, 2017. 